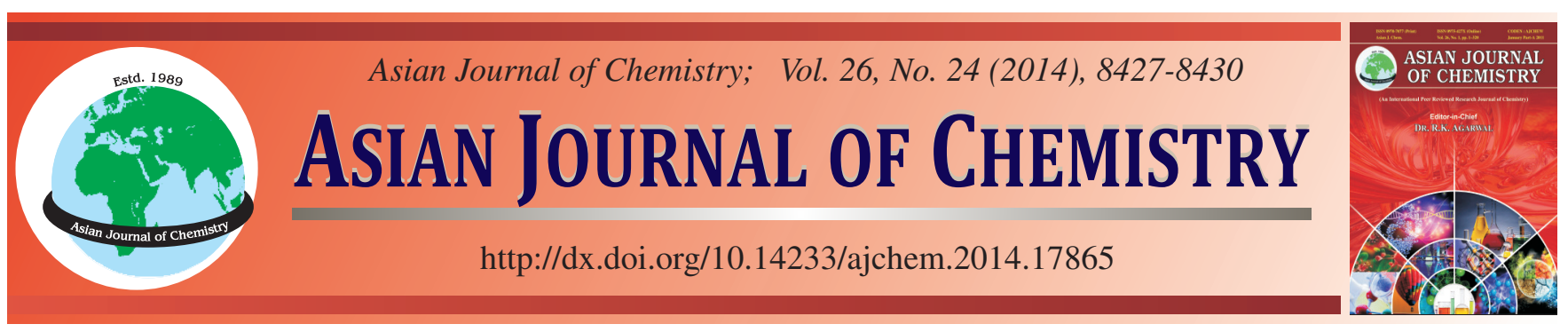

\title{
Crystal Structure, Photoluminescent and Theoretical Studies of 3-Acetyl-8-methoxy-coumarin Derivatives
}

\author{
XIN $\mathrm{SHU}^{1}, \mathrm{JING}^{2}{ }^{2}$ and MING-KAI $\mathrm{LI}^{1, *}$ \\ ${ }^{1}$ Department of Pharmacology, School of Pharmacy, The Fourth Military Medical University, Xi'an, P.R. China \\ ${ }^{2}$ School of Chemistry and Chemical Engineering, Xi'an University, Xi'an, P.R. China \\ *Corresponding author: E-mail: mingkai@fmmu.edu.cn
}

Received: 21 April 2014;

Accepted: 7 July 2014;

Published online: 1 December 2014;

AJC-16375

\begin{abstract}
3-Acetyl-8-methoxy-coumarin and its derivative 3-(2,2'-dibromoacetyl)-8-methoxy-coumarin were synthesized and characterized. The structure of 3-(2,2'-dibromoacetyl)-8-methoxy-coumarin was verified by single-crystal X-ray crystallography. The UV-visible absorption and fluorescence of 3-acetyl-8-methoxy-coumarin and 3-(2,2'-dibromoacetyl)-8-methoxy-coumarin were also studied. Both compounds exhibit strong blue emission under ultraviolet light excitation. The molecular structure of 3-(2,2'-dibromoacetyl)-8-methoxy-coumarin was optimized using density functional theory at the B3LYP/6-31G(d) level, showing that the optimized geometer parameters are in good agreement with the experimental data. In addition, the HOMO and LUMO levels of 3-acetyl-8-methoxy-coumarin and 3-(2,2'dibromoacetyl)-8-methoxy-coumarin were deduced.
\end{abstract}

Keywords: Coumarin, Crystal structure, UV-visible, Fluorescence, Density functional theory.

\section{INTRODUCTION}

In recent years, coumarin and its derivatives have been representing an important class of organic heterocycles. They have received considerable attention because of their widespread usage in several fields.

They possess a wide range of biological activities ${ }^{1,2}$, including antiinflammatory, anticancer, antifungal, antimicrobial, antiviral, anticoagulant, antituberculosis, anti-HIV and anticarcinogenic activities. Moreover, this group of compounds possess unique photochemical and photophysical properties ${ }^{3,4}$, including sufficient fluorescence in the visible light range, high quantum yields, large Stokes shift, superior photostability and good solubility in common solvents. Consequently, they are very useful in a variety of applications ${ }^{5,6}$, such as in optical brighteners, laser dyes, non-linear optical chromophores, solar energy collectors, fluorescent labels and probes in biology and medicine, as well as in two-photon absorption materials. For example, 3-acetylcoumarin displays polymorphism, while many of its derivatives like the title compound 3-acetyl-8methoxy-coumarin (ACM, Fig. 1) are effective anticancer agents or have been proposed as sensitizers for light-sensitive materials ${ }^{7}$. In this study, we synthesized a new compound 3(2,2'-dibromoacetyl)-8-methoxy-coumarin (DMC, Fig. 1) from the compound 3-acetyl-8-methoxy-coumarin and then studied their photophysical properties.<smiles>COc1cccc2cc(C(C)=O)c(=O)oc12</smiles>

AMC<smiles>COc1cccc2cc(C(=O)C(Br)Br)c(=O)oc12</smiles>

DMC
Fig. 1. Chemical structure of 3-acetyl-8-methoxy-coumarin (AMC) and 3-(2,2'-dibromoacetyl)-8-methoxy-coumarin (DMC)

\section{EXPERIMENTAL}

IR spectra (4000-400 $\left.\mathrm{cm}^{-1}\right)$ were obtained using a Brucker Equinox-55 spectrophotometer. ${ }^{1} \mathrm{H}$ NMR spectra were obtained using a Varian Inova-400 spectrometer (at $400 \mathrm{MHz}$ ). Mass spectra were obtained using a micrOTOF-Q II mass spectrometer. The melting points were taken on a XT-4 micro melting apparatus and the thermometer was uncorrected. UV-visible absorption and emission spectra were recorded using a thermo evolution 300 spectrometer and a cary eclipse spectrometer, respectively. All the chemicals were commercially available and used without further purification. All the solvents were dried using standard methods before use.

Synthesis: 3-Methoxysalicylaldehyde (15.2 g, $0.1 \mathrm{~mol})$, ethylacetoacetate $(12.6 \mathrm{~mL}, 0.1 \mathrm{~mol})$, piperidine $(2 \mathrm{~mL})$ and ethanol $(200 \mathrm{~mL})$ were mixed in a $500 \mathrm{~mL}$ round-bottomed 
flask, refluxed under magnetic stirring for $4 \mathrm{~h}$ and cooled to room temperature. The yellowish solid was filtered off and then recrystallized from ethanol to give 3-acetyl-8-methoxycoumarin $^{8}$.

3-Acetyl-8-methoxy-coumarin (AMC): m.p. $173-174{ }^{\circ} \mathrm{C}$. ${ }^{1} \mathrm{H} \mathrm{NMR}\left(\mathrm{CDCl}_{3}, \delta\right.$, ppm): 2.732 (s, 3H), 3.988 (s, 3H), 7.177$7.284(\mathrm{~m}, 3 \mathrm{H}), 8.480$ (s, 1H). ESI-MS: $m / z 219[\mathrm{M}+1]^{+}$.

3-(2,2'-Dibromoacetyl)-8-methoxy-coumarin (DMC) was obtained by the reaction of 3-acetyl-coumarin with bromine as described in literature ${ }^{9}$ and recrystallized from chloroform/ ethanol solution at room temperature to give the desired crystals suitable for single crystal X-ray diffraction.

3-(2,2'-Dibromoacetyl)-8-methoxy-coumarin (DMC): m.p. $165-166{ }^{\circ} \mathrm{C} .{ }^{1} \mathrm{H}$ NMR $\left(\mathrm{CDCl}_{3}, \delta, \mathrm{ppm}\right): 2.622$ (s, 3H), 4.158 (s, 1H), 6.247-6.884 (m, 3H), 8.720 (s, 1H). ESI-MS: $\mathrm{m} / \mathrm{z} 376[\mathrm{M}+1]^{+}$.

Determination of crystal structure: The $\mathrm{X}$-ray diffraction data of compound 3-(2,2'-dibromoacetyl)-8-methoxy-coumarin were collected on a Bruker SMART APEX II CCD diffractometer equipped with a graphite monochromated $\mathrm{MoK}_{\alpha}$ radiation ( $\lambda=0.71073 \AA$ ) by using the $\omega$ - $2 \theta$ scan technique at room temperature. The structure was solved by direct methods using SHELXS-97 and refined using the full-matrix least squares method on $\mathrm{F}^{2}$ with anisotropic thermal parameters for all non-hydrogen atoms by using SHELXL-9 ${ }^{10}$. Hydrogen atoms were generated geometrically. The crystal data and details concerning data collection and structure refinement are given in Table-1. Molecular illustrations were prepared using the XP package. Parameters in CIF format are available as Electronic Supplementary Publication from Cambridge Crystallographic Data Centre.

\begin{tabular}{|c|c|}
\hline \multicolumn{2}{|c|}{$\begin{array}{c}\text { TABLE-1 } \\
\text { CRYSTAL DATA, DATA COLLECTION AND } \\
\text { STRUCTURE REFINEMENT OF COMPOUND } \\
\text { 3-(2,2'-DIBROMOACETYL)-8-METHOXY-COUMARIN }\end{array}$} \\
\hline Formula & $\mathrm{C}_{12} \mathrm{H}_{8} \mathrm{O}_{4} \mathrm{Br}_{2}$ \\
\hline $\mathrm{M}_{\mathrm{r}}$ & 373.88 \\
\hline Temperature (K) & 273 \\
\hline Crystal system & Monoclinic \\
\hline Space group & $\mathrm{P} 2_{1} / \mathrm{n}$ \\
\hline $\mathrm{a} / \AA$ & $6.970(2)$ \\
\hline $\mathrm{b} / \AA ̊ \AA$ & $24.954(8)$ \\
\hline $\mathrm{c} / \AA ̊ \AA$ & $7.016(2)$ \\
\hline$\alpha^{\circ}$ & 90 \\
\hline$\beta /^{\circ}$ & $103.802(4)$ \\
\hline$\gamma /{ }^{\circ}$ & 90 \\
\hline $\mathrm{V} / \AA^{3}$ & $1184.9(7)$ \\
\hline $\mathrm{Z}$ & 4 \\
\hline $\mathrm{D}_{\text {calc }} / \mathrm{g} \mathrm{cm}^{-03}$ & 2.108 \\
\hline$\mu\left(\mathrm{MoK}_{\alpha}\right) / \mathrm{mm}^{-1}$ & 6.844 \\
\hline$\theta$ range $/{ }^{\circ}$ & 1.6 to 28.2 \\
\hline Reflections collected & 9821 \\
\hline No. unique data[R(int)] & $2094[0.0517]$ \\
\hline No. data with $I \geq 2 \sigma(I)$ & 1679 \\
\hline $\mathrm{R}_{1}$ & 0.0241 \\
\hline$\omega \mathrm{R}_{2}$ (all data) & 0.0531 \\
\hline CCDC & 989310 \\
\hline
\end{tabular}

Quantum chemical calculation: The structures of 3acetyl-8-methoxy-coumarin and 3-(2,2'-dibromoacetyl)8 -methoxy-coumarin were optimized by density functional theory (DFT) using a B3LYP/6-31G(d) basis set. The structure optimization and energy calculations were performed with the GAUSSIAN 09 program.

\section{RESULTS AND DISCUSSION}

Crystal structure description: The crystal structure of 3 -(2,2'-dibromoacetyl)-8-methoxy-coumarin is given in Fig. 2. The selected bond lengths and bond angles of 3-(2,2'dibromoacetyl)-8-methoxy-coumarin are listed in Table-2.

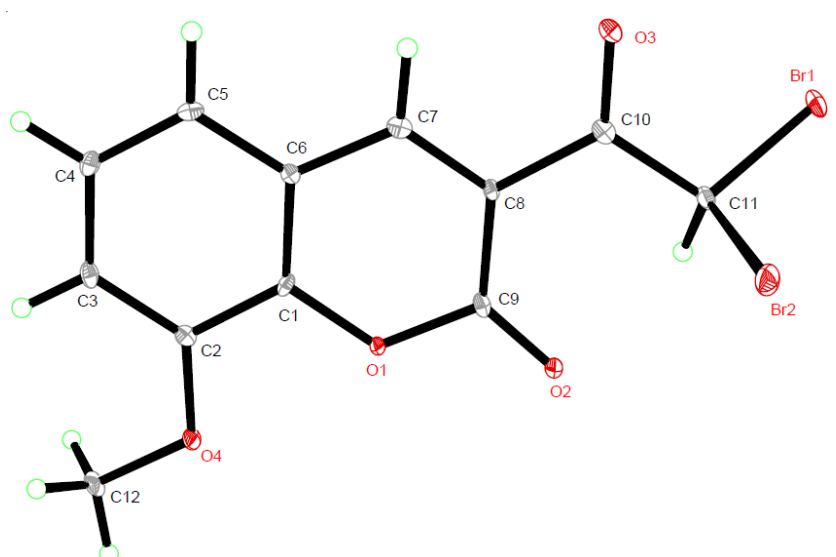

Fig. 2. Crystal structure of 3-(2,2'-dibromoacetyl)-8-methoxy-coumarin (DMC)

TABLE-2

EXPERIMENTAL AND CALCULATED PARAMETERS OF THE SELECTED BOND LENGTHS AND BOND ANGLES OF 3(2,2'-DIBROMOACETYL)-8-METHOXY-COUMARIN

\begin{tabular}{lcc}
\multicolumn{1}{c}{ Parameter } & \multicolumn{2}{c}{ DMC } \\
\hline \multicolumn{1}{c}{ Bond length $(\AA)$} & X-ray & Calculation \\
\hline $\mathrm{O}(1)-\mathrm{C}(1)$ & 1.368 & 1.359 \\
$\mathrm{O}(1)-\mathrm{C}(9)$ & 1.392 & 1.390 \\
$\mathrm{O}(2)-\mathrm{C}(9)$ & 1.211 & 1.210 \\
$\mathrm{O}(3)-\mathrm{C}(10)$ & 1.213 & 1.215 \\
$\mathrm{O}(4)-\mathrm{C}(2)$ & 1.357 & 1.354 \\
$\mathrm{O}(4)-\mathrm{C}(12)$ & 1.443 & 1.422 \\
$\mathrm{C}(8)-\mathrm{C}(10)$ & 1.514 & 1.502 \\
\hline \multicolumn{1}{c}{ Angle $\left(^{\circ}\right)$} & X-ray & Calculation \\
\hline $\mathrm{C}(1)-\mathrm{O}(1)-\mathrm{C}(9)$ & 122.5 & 123.5 \\
$\mathrm{C}(2)-\mathrm{O}(4)-\mathrm{C}(12)$ & 116.2 & 118.2 \\
$\mathrm{O}(1)-\mathrm{C}(1)-\mathrm{C}(2)$ & 117.2 & 117.3 \\
$\mathrm{O}(4)-\mathrm{C}(2)-\mathrm{C}(3)$ & 125.8 & 125.9 \\
$\mathrm{C}(9)-\mathrm{C}(8)-\mathrm{C}(10)$ & 121.9 & 122.9 \\
$\mathrm{O}(2)-\mathrm{C}(9)-\mathrm{O}(1)$ & 115.6 & 116.7 \\
$\mathrm{O}(1)-\mathrm{C}(9)-\mathrm{C}(8)$ & 116.3 & 116.0 \\
$\mathrm{O}(3)-\mathrm{C}(10)-\mathrm{C}(8)$ & 119.8 & 120.4 \\
$\mathrm{C}(11)-\mathrm{C}(10)-\mathrm{C}(8)$ & 118.7 & 118.1 \\
\hline
\end{tabular}

Fig. 2 shows that the 3-(2,2'-dibromoacetyl)-8-methoxycoumarin molecule is essentially planar because its lactone and benzene rings are inclined only $0.171(88)^{\circ}$ to one another. The maximum deviation of the atoms in the skeleton (the lactone and benzene rings) from the molecular plane $(\mathrm{C}(1)-$ $\mathrm{C}(9) / \mathrm{O}(1))$ is only $0.0175 \AA$. The $\mathrm{O}(2) / \mathrm{C}(9) / \mathrm{O}(1)$ and $\mathrm{C}(2) /$ $\mathrm{O}(4) / \mathrm{C}(12)$ planes are inclined $1.057(284)$ and $6.261(228)^{\circ}$, respectively to the molecular plane. However, the $\mathrm{O}(3) / \mathrm{C}(10) /$ $\mathrm{C}(11)$ plane makes a $3.128(271)^{\circ}$ angle with the molecular plane and atoms $\mathrm{O}(3)$ and $\mathrm{C}(11)$ deviate from that plane by 0.0105 and $0.1154 \AA$, respectively. In addition, the $\mathrm{C}(2)-\mathrm{O}(4)$ bond (1.3568(36) $\AA$ ) is significantly shorter than $\mathrm{C}(12)-\mathrm{O}(4)$ 
(1.4426(31) §), indicating a donation of the electrons from the $\mathrm{O}$ atom to the aromatic ring.

Strong intermolecular hydrogen bonds are also observed in the structure. These hydrogen bonds link the molecules together to form planar structures, which are further held together via $\pi$ - $\pi$ stacking interactions to form a three-dimensional supramolecular architecture. Finally, the molecules are assembled to form a layer structure (Fig. 3).

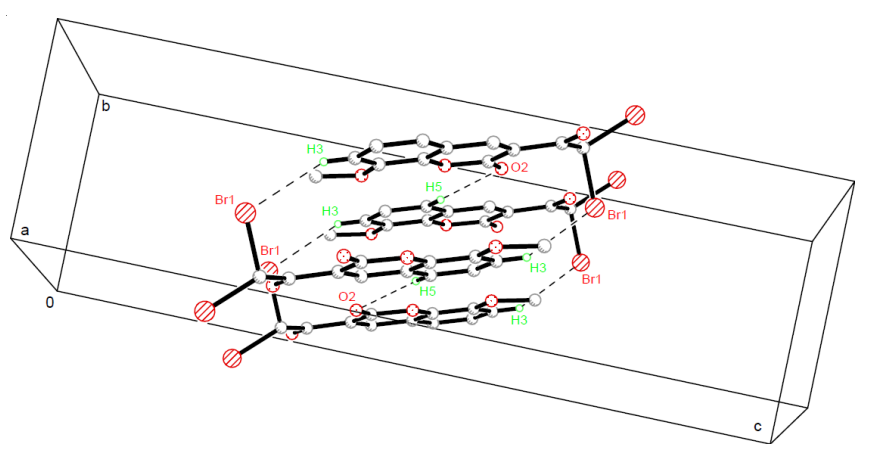

Fig. 3. Packing diagram in a unit cell

UV-visible absorption and photoluminescence of 3acetyl-8-methoxy-coumarin and 3-(2,2'-dibromoacetyl)-8methoxy-coumarin: The UV-visible absorption and photoluminescence spectra of 3-acetyl-8-methoxy-coumarin and 3 -(2,2'-dibromo-acetyl)-8-methoxy-coumarin in diluted dichloromethane solutions are shown in Fig. 4. The absorption spectrum of coumarin has a sharp absorption peak at $281 \mathrm{~nm}$, with a shoulder at $320 \mathrm{~nm}^{11}$. 3-Acetyl-8-methoxy-coumarin only has intense absorption at $316 \mathrm{~nm}$, which is red-shifted with respect to the sharp absorption peak of coumarin. The difference in the absorption features of 3-acetyl-8-methoxycoumarin and coumarin may be attributed to the introduction of an electron-attracting acetyl group to the 3-position of coumarin ring and an electron-repelling methoxyl group to the 8-position, thereby resulting in a stronger intramolecular charge transfer.

In addition, the absorption peak at $330 \mathrm{~nm}$ of compound 3-(2,2'-dibromoacetyl)-8-methoxy-coumarin is red-shifted compared with that of compound 3-acetyl-8-methoxy-coumarin as a result of two electron-attracting chlorine atoms in the acetyl group, which increase the effect of intramolecular charge transfer.

Fig. 4 also shows the photoluminescence spectra of 3acetyl-8-methoxy-coumarin and 3-(2,2'-dibromoacetyl)-8methoxy-coumarin in diluted dichloromethane solutions. The compound 3-(2,2'-dibromoacetyl)-8-methoxy-coumarin exhibits a bright blue emission, with a maximum emission peak at $484 \mathrm{~nm}$, which is red-shifted by about $26 \mathrm{~nm}$ with respect to that of compound 3-acetyl-8-methoxy-coumarin at $458 \mathrm{~nm}$ because of the greater strength of the intra-molecular charge transfer upon the introduction of two chlorine atoms to the 3-acetyl group.

Quantum chemical calculations: B3LYP/6-31G(d) optimized structure of 3-(2,2'-dibromoacetyl)-8-methoxy-coumarin is close to its X-ray crystal structure. B3LYP/6-31G(d) optimized geometrical data of 3-(2,2'-dibromoacetyl)-8-methoxycoumarin is in good agreement with the X-ray crystallographic

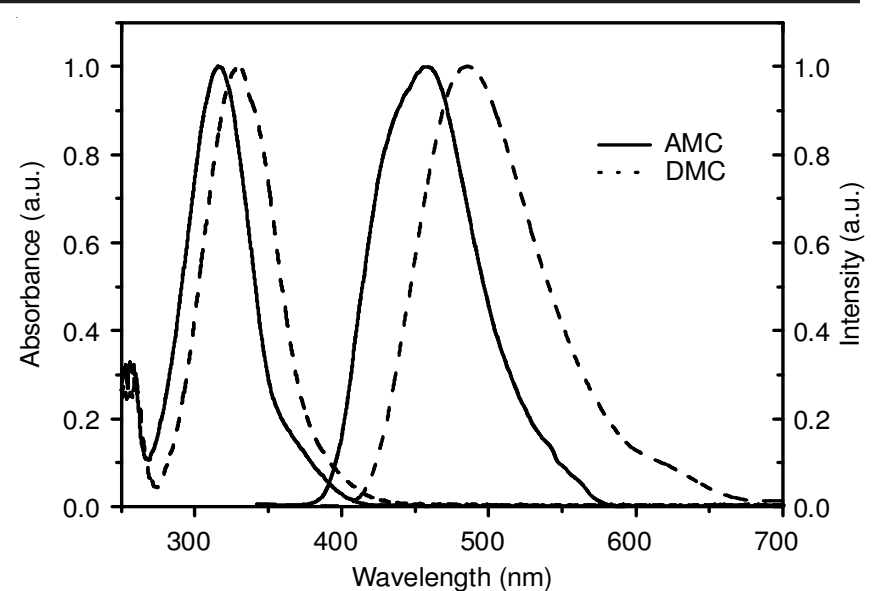

Fig. 4. Normalized UV-visible absorption and emission spectra of 3-acetyl8-methoxy-coumarin and 3-(2,2'-dibromoacetyl)-8-methoxycoumarin in diluted dichloromethane solutions

data, as listed in Table-1. The average discrepancy of the selected bond lengths between theoretical and experimental data is less than $\pm 0.02 \AA$ and the average discrepancy of the selected bond angles is less than $\pm 2^{\circ}$. Therefore, the results using density functional theory (DFT) at the B3LYP/6-31G(d) level are creditable.

The HOMO and LUMO levels of 3-acetyl-8-methoxycoumarin and 3-(2,2'-dibromoacetyl)-8-methoxy-coumarin were deduced using density functional theory method (Fig. 5), which is essential for deducing their $S_{0}$ and $S_{1}$ states. This knowledge is important for better understanding of their fluorescence and nonlinear optical properties.
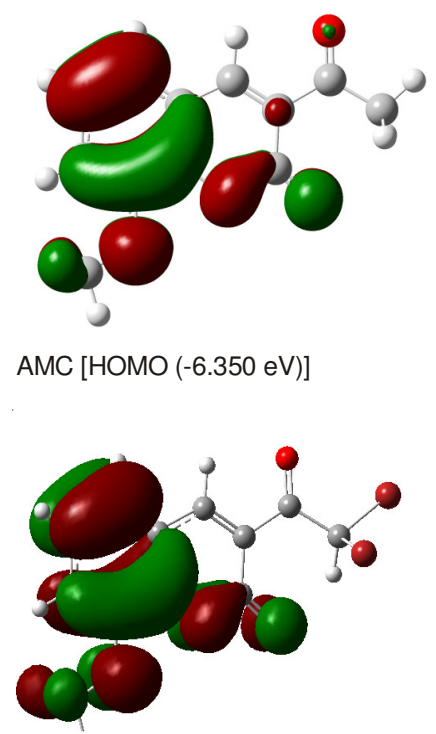

DMC [HOMO (-6.210 eV)]
AMC [HOMO (-6.350 eV)]

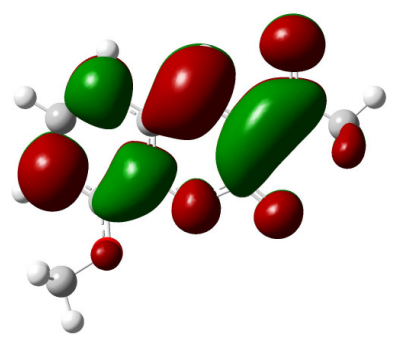

AMC [LUMO (-2.394 eV)]



Fig. 5. HOMO and LUMO electron distributions of 3-acetyl-8-methoxycoumarin (AMC) and 3-(2,2'-dibromoacetyl)-8-methoxy-coumarin (DMC)

The HOMO and LUMO diagrams of 3-acetyl-8-methoxycoumarin and 3-(2,2'-dibromoacetyl)-8-methoxy-coumarin show that the two compounds are likely to exhibit an efficient electron transfer from the benzene ring of HOMO to the whole molecular skeleton of LUMO if electronic transitions occur. 
The HOMO for the two compounds is localized at the benzene ring, whereas the LUMO at the whole coumarin moiety. Therefore, when electrons transfer from HOMO to LUMO, the electron density significantly decreases in the electron-donating benzene ring system, accompanied by an increase in the electron density of the electron accepting lactone ring system. This indicates that the electrons transfer from the benzene ring to the lactone ring.

Based on the optimized structure, the HOMO and LUMO levels of 3-acetyl-8-methoxy-coumarin are -6.350 and -2.394 $\mathrm{eV}$, respectively and the energy gap between HOMO and LUMO is approximately $3.956 \mathrm{eV}$. The corresponding levels for 3-(2,2'-dibromoacetyl)-8-methoxy-coumarin are -6.210 and $-2.514 \mathrm{eV}$ and the relative energy gap is $3.696 \mathrm{eV}$. The value of the energy gap of 3-(2,2'-dibromoacetyl)-8-methoxycoumarin to be lower than that of 3-acetyl-8-methoxy-coumarin, which leads to the absorption peak of 3-(2,2'-dibromo-acetyl)8-methoxy-coumarin to be bathochromically shifted compared with that of 3-acetyl-8-methoxy-coumarin.

\section{ACKNOWLEDGEMENTS}

This research was supported by grants from the Innovation plan of science and technology of Shaanxi Province (2014KTCL03-03).

\section{REFERENCES}

1. K.C. Fylaktakidou, D.J. Hadjipavlou-Litina, K.E. Litinas and D.N. Nicolaides, Curr. Pharm. Des., 10, 3813 (2004).

2. L.K.A.M. Leal, A.A.G. Ferreira, G.A. Bezerra, F.J.A. Matos and G.S.B. Viana, J. Ethnopharmacol., 70, 151 (2000).

3. H. Zhang, T.Z. Yu, Y.L. Zhao, D.W. Fan, L. Qian, C.H. Yang and K. Zhang, Spectrochim. Acta A, 68, 725 (2007).

4. H. Zhang, T.Z. Yu, Y.L. Zhao, D.W. Fan, L.L. Chen, Y.Q. Qiu, L. Qian, K. Zhang and C.H. Yang, Spectrochim. Acta A, 69, 1136 (2008).

5. H. Turki, S. Abid, S. Fery-Forgues and R. El Gharbi, Dyes Pigments, 73, 311 (2007).

6. C. Féau, E. Klein, P. Kerth and L. Lebeau, Bioorg. Med. Chem. Lett., 17, 1499 (2007).

7. H.M. Han, C.R. Lu, Y. Zhang, D.C. Zhang, Acta. Cryst., E61, o1864 (2005).

8. J. Li, Y. He, X. Ren, X. Shi, S. Yang, X. Gao and G. Huang, Chinese J. Struct. Chem., 31, 1003 (2013).

9. H.A. Sparkes and J.A.K. Howard, Acta Crystallogr., 63E, o3895 (2007).

10. G.M. Sheldrick, SHELXS 97, Program for the Solution of Crystal Structure, University of Göttingen, Germany (1997).

11. T.Z. Yu, Y.L. Zhao and D.W. Fan, J. Mol. Struct., 791, 18 (2006). 